\title{
Research Square \\ Correction of some thermodynamic surface properties of Sodium Alginate determined by Inverse Gas Chromatography
}

Tayssir Hamieh ( $\sim$ tayssir.hamieh@ul.edu.lb )

MCEMA and LEADDER Laboratories, Faculty of Sciences and EDST, Lebanese University, Hariri Campus, Hadath, Beirut, Lebanon. Khalet Zarzour, Kfarhatta, Saida, Lebanon https://orcid.org/0000-0003-21537408

\section{Research Article}

Keywords: Dispersive component of surface energy of solid, specific enthalpy of adsorption, acid base constant in Lewis terms, inverse gas chromatography

Posted Date: April 6th, 2021

DOl: https://doi.org/10.21203/rs.3.rs-393195/v1

License: (c) (i) This work is licensed under a Creative Commons Attribution 4.0 International License. Read Full License 


\section{Correction of some thermodynamic surface properties of Sodium}

\section{Alginate determined by Inverse Gas Chromatography}

Tayssir Hamieh ${ }^{\prime 2}$

'MCEMA and LEADDER Laboratories, Faculty of Sciences and EDST, Lebanese University, Hariri Campus, Hadath, Beirut, Lebanon. Khalet Zarzour, Kfarhatta, Saida, Lebanon

${ }^{2}$ SATIE-IFSTTAR, University Gustave Eiffel, Campus de Marne-La-Vallée, University Gustave Eiffel, 25, allée des Marronniers, 78000 Versailles, France.

Orcid.org/0000-0003-2153-7408; Email: tayssir.hamieh@ul.edu.lb

KEYWORDS. Dispersive component of surface energy of solid; specific enthalpy of adsorption; acid base constant in Lewis terms; inverse gas chromatography.

ABSTRACT. In their paper published in the Journal of Chemical Engineering Data, Ugraskan et al. [1] made several inaccuracies in the determination of the surface properties of sodium alginate by using the inverse gas chromatography (IGC) technique. The proposed method to determine the dispersive component of the surface energy, $\gamma_{s}^{d}$, cannot be correctly evaluated, because it depends on the surface area of n-alkanes or of methylene group. This surface area supposed by Ugraskan et al. [1] constant strongly depends on the temperature. Therefore, the specific free energy of adsorption, $\left(-\Delta G^{s p}\right)$, and consequently the specific enthalpy of adsorption, $\left(-\Delta H^{s p}\right)$, cannot be 
known with accuracy. The wrong values of $\left(-\Delta H^{s p}\right)$, certainly lead to inaccurate determination of the acid $K_{A}$ and base $K_{D}$ constants of the solid.

\section{ITRODUCTION}

Inverse gas chromatography (IGC) technique is a real source of physiochemical data of surfaces and interfaces allowing the determination of the specific interactions between oxides, polymers or polymers adsorbed on oxides and organic solvent systems [2-5]. This is an important tool, precise, sensitive, and more competitive to determine the heterogeneous surfaces of solids, their physicochemical properties [6], and to determine surface energy and surface area of powdered materials [7-10]. This IGC technique can advantageously determine the surface properties of solid materials, and especially, the Lewis acid base properties and mainly the adsorption thermodynamic parameters as specific free energy, enthalpy and entropy of adsorption, Lewis acid-base character of the surface, surface nanoroughness parameter, etc. [11-19].

In this paper, we propose to correct the surface properties determined by Ugraskan et al. [1]. In fact, these authors had used the Schultz et al. [20] and Dorris-Gray [21] methods, both, based on Fowkes relation [22]. The major problem of this method is the exact knowledge of the surface area of n-alkanes. Because the above method always supposed the surface area of n-alkanes constant. However, Hamieh et al. [23] proved that the surface area of molecules depends on the temperature. Consequently, the specific free energy, enthalpy and entropy of adsorption of polar molecules become inaccurate and this leads to wrong values of the acid base constants of the solid. 


\section{METHODS AND CRITIQUES}

\subsection{Dorris and Gray method or the increment method}

Dorris and Gray [21] proposed the increment method by applying the well-known relationship of Fowkes which gives at the same time the dispersive component of the surface energy of solids $\gamma_{S}^{d}$ by using the geometric mean of the dispersive components (exponent $d$ ) of the surface energy of the probe $\gamma_{l}^{d}$ and the solid $\gamma_{s}^{d}$ :

$$
W_{a}=2 \sqrt{\gamma_{l}^{d} \gamma_{s}^{d}}
$$

Where $W_{a}$ is the work of adhesion between the probe and the solid.

This energy of adhesion was correlated to the free enthalpy of adsorption

$$
\Delta G^{o}=\mathcal{N} a W_{a}=2 \mathcal{N} a \sqrt{\gamma_{l}^{d} \gamma_{s}^{d}}
$$

Where $\mathcal{N}$ is Avogadro's number and $a$ the surface area of one adsorbed molecule on the solid.

Dorris and Gray [21] were the first who determined the dispersive component of the surface energy of a solid by considering the increment of $\Delta G_{-C H 2}^{0}$ per methylene group in the n-alkanes series of general formula $C_{n} H_{2(n+1)}$. They defined the increment $\Delta G_{-C H 2-}^{0}$ by:

$$
\Delta G_{-C H 2-}^{0}=\Delta G^{0}\left(C_{n+1} H_{2(n+2)}\right)-\Delta G^{0}\left(C_{n} H_{2(n+1)}\right)
$$

Where $C_{n} H_{2(n+1)}$ and $C_{n} H_{2(n+1)}$ represents the general formula of two consecutive n-alkanes.

By using the retention volumes $V_{n}\left(C_{n} H_{2(n+1)}\right)$ and $V_{n}\left(C_{n+1} H_{2(n+2)}\right)$ of two consecutive n-alkanes and relation (2), the dispersive component of the surface energy $\gamma_{s}^{d}$ can be determined by the following equation:

$$
\gamma_{S}^{d}=\frac{\left[R T \ln \left[\frac{V_{n}\left(C_{n+1} H_{2(n+2)}\right)}{V_{n}\left(C_{n} H_{2(n+1)}\right)}\right]\right]^{2}}{4 \mathcal{N}^{2} a_{-C H 2-}^{2} \gamma_{-C H 2-}}
$$




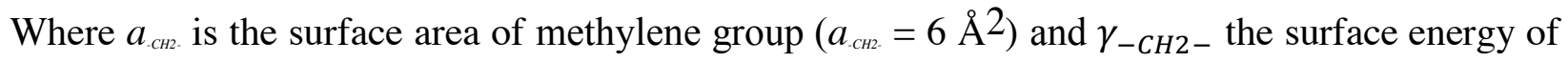
- $\mathrm{CH} 2$ - group of a polyethylene polymer (with a finite molecular mass) given by:

$$
\gamma_{-\mathrm{CH}_{2}-}=52.603-0.058 \mathrm{~T} \quad\left(\mathrm{~T} \text { in } \mathrm{K} ; \gamma_{-C H 2-} \text { in } \mathrm{mJ} / \mathrm{m}^{2}\right)
$$

Therefore, relation (4) determined the dispersive component of the surface energy $\gamma_{s}^{d}$ of solids.

\subsection{Schultz et al. method or the n-alkane straight-line method}

This method also based on Fowkes approach [22] replaced the free enthalpy of adsorption by its values taken from relation (1) to obtain the following relationship:

$$
R T \ln V n+C=2 \mathcal{N} a \sqrt{\gamma_{l}^{d} \gamma_{s}^{d}}
$$

By plotting $R T \ln V n$ as a function of $2 \mathcal{N} a \sqrt{\gamma_{l}^{d}}$ of n-alkanes, one obtains a typical straight line that allows to deduce, from its slope, the value of dispersive component $\gamma_{s}^{d}$ of the surface energy of the solid.

The two previous methods use the value of the surface area $a$ of n-alkanes of the methylene group and suppose that these values of $a$ remain constant whatever the temperature. In general, the values of surface areas of n-alkanes used are those proposed by Kiselev (see Table 1). Hamieh et al proposed several molecular models $[23,24]$ to determine the surface areas of molecules (Table 1). They proved the effect of the temperature on the surface area of n-alkanes and polar molecules [24]. 
Tableau 1. Surface areas of various molecules (in $\AA^{2}$ ) obtained from the various models of Van der Waals (VDW), Redlich-Kwong (R-K) and Kiselev, compared to those obtained by geometrical, cylindrical or spherical models.

\begin{tabular}{ccccccc}
\hline Molecule & $\begin{array}{c}\text { VDW } \\
\left(\text { in } \AA^{2}\right)\end{array}$ & $\begin{array}{c}\text { Kiselev } \\
\left(\text { in } \AA^{2}\right)\end{array}$ & $\begin{array}{c}\text { Cylindrical } \\
\left(\text { in } \AA^{2}\right)\end{array}$ & $\begin{array}{c}\text { R-K } \\
\left(\text { in } \AA^{2}\right)\end{array}$ & $\begin{array}{c}\text { Spherical } \\
\left(\text { in } \AA^{2}\right)\end{array}$ & $\begin{array}{c}\text { Geometrical } \\
\left(\text { in } \AA^{2}\right)\end{array}$ \\
\hline $\mathbf{C}_{5} \mathbf{H}_{12}$ & 47.0 & 45 & 39.3 & 36.8 & 36.4 & 32.9 \\
\hline $\mathbf{C}_{6} \mathbf{H}_{14}$ & 52.7 & 51.5 & 45.5 & 41.3 & 39.6 & 40.7 \\
\hline $\mathbf{C}_{6} \mathbf{H}_{16}$ & 59.2 & 57 & 51.8 & 46.4 & 42.7 & 48.5 \\
\hline $\mathbf{C}_{8} \mathbf{H}_{18}$ & 64.9 & 63 & 58.1 & 50.8 & 45.7 & 56.2 \\
\hline $\mathbf{C}_{9} \mathbf{H}_{20}$ & 69.6 & 69 & 64.4 & 54.5 & 48.7 & 64.0 \\
\hline $\mathbf{C}_{10} \mathbf{H}_{22}$ & 74.4 & 75 & 70.7 & 58.2 & 51.7 & 71.8 \\
\hline
\end{tabular}

Hamieh et al. [24] showed the areas $a(\mathrm{~T})$ of polar molecules adsorbed on Polytetrafluoroethylene (PTFE), linearly depend on the temperature. The following relation was proved:

$$
a(T)=a_{0}-\Omega T
$$

with $\Omega$ the slope of the straight line depending on the nature of the adsorbed molecule and solid substrate, $a(T)$ the surface area at temperature $T$ and $a_{0}$ the molecule area extrapolated at $0 \mathrm{~K}$.

Therefore, it will be impossible to deduce a precise value of the specific interaction for one polar molecule by using this method, because the surface areas of adsorbed molecules cannot be accurately determined. The limitations of Schultz et al and Dorris-Gray methods are due, in part, to the fact that the molecular area $a$ is not exactly known and varies both with the nature of the solid, and the temperature and surface coverage of molecule on the solid surface. 


\section{RESULTS}

\subsection{New results on the determination of the dispersive component of the surface energy of}

sodium alginate

In the calculation of $\gamma_{s}^{d}$, Ugraskan et al. [1] not only supposed the surface areas constant but there is probably a certain error committed by considering constant the value of the dispersive component $\gamma_{l}^{d}$ of the surface energy of organic molecules when the temperature changes. In fact, $\gamma_{l}^{d}$ also depends on the temperature. On Table 2, we gave the different values of $\gamma_{l}^{d}$ of n-alkanes and polar molecules versus the temperature.

Table 2. Values of $\gamma_{l}^{d}\left(\mathrm{~mJ} / \mathrm{m}^{2}\right)$ of molecules as a function of the temperature

\begin{tabular}{|c|c|c|c|c|c|c|}
\hline $\begin{array}{l}\text { Temperature } \\
\text { Molecules }\end{array}$ & $303.2 \mathrm{~K}$ & $308.2 \mathrm{~K}$ & $313.2 K$ & $318.2 \mathrm{~K}$ & $323.2 K$ & $328.2 K$ \\
\hline C6 & 17.35 & 16.84 & 16.33 & 15.82 & 15.31 & 14.80 \\
\hline C7 & 19.14 & 18.65 & 18.16 & 17.67 & 17.18 & 16.69 \\
\hline $\mathrm{C8}$ & 20.68 & 20.21 & 19.73 & 19.25 & 18.78 & 18.30 \\
\hline C9 & 21.86 & 21.39 & 20.93 & 20.46 & 19.99 & 19.53 \\
\hline $\mathrm{C10}$ & 22.89 & 22.43 & 21.97 & 21.51 & 21.05 & 20.59 \\
\hline Acetone & 19.22 & 18.78 & 18.35 & 17.92 & 17.48 & 17.05 \\
\hline THF & 25.07 & 24.40 & 23.73 & 23.06 & 22.39 & 21.72 \\
\hline $\mathrm{CH}_{2} \mathrm{Cl}_{2}$ & 26.40 & 25.53 & 24.66 & 23.79 & 22.92 & 22.05 \\
\hline Chloroform & 22.02 & 20.55 & 19.08 & 17.61 & 16.14 & 14.67 \\
\hline Ethyl acetate & 22.49 & 21.89 & 21.29 & 20.68 & 20.08 & 19.48 \\
\hline
\end{tabular}


By taking into account the variations of $\gamma_{l}^{d}$ as a function of the temperature, we were able to correct the values of $\gamma_{s}^{d}$ following the Fowkes method. The results are presented on Table 3 .

Table3. Values of the dispersive component of the surface energy $\gamma_{s}^{d}\left(\mathrm{~mJ} / \mathrm{m}^{2}\right)$ of Sodium Alginate by using Kiselev surface areas.

\begin{tabular}{cc}
\hline Temperature (K) & $\gamma_{S}^{d}\left(\mathbf{m} \mathbf{J} / \mathbf{m}^{2}\right)$ \\
\hline 303.2 & 44.44 \\
\hline 308.2 & 44.22 \\
\hline 313.2 & 43.30 \\
\hline 318.2 & 42.93 \\
\hline 323.2 & 42.63 \\
\hline 328.2 & 41.95 \\
\hline
\end{tabular}

The above values were obtained by taking the proposed results of Kiselev used for the surface areas of n-alkanes. Table 3 shows a difference of $2.33 \mathrm{~mJ} / \mathrm{m}^{2}$ between our values and those of Table 2 obtained by Ugraskan et al. [1], probably due to their hypothesis that supposed $\gamma_{l}^{d}$ constant.

Now, in order to prove the dependency of $\gamma_{s}^{d}$ of solids on the choice of the molecular area models, we present in Table 4 our results obtained for the dispersive component of the surface area of sodium alginate for the different molecular surface area models. 
Table4. Values of the dispersive component of the surface energy $\gamma_{s}^{d}\left(\mathrm{~mJ} / \mathrm{m}^{2}\right)$ of Sodium Alginate by using other molecular surface area models.

\begin{tabular}{cccccc}
\hline $\begin{array}{c}\text { Area model } \\
\text { Temperature }\end{array}$ & $\begin{array}{c}\text { VDW } \\
\left(\mathrm{mJ} / \mathrm{m}^{2}\right)\end{array}$ & $\begin{array}{c}\text { Cylindrical } \\
\left(\mathrm{m} / / \mathrm{m}^{2}\right)\end{array}$ & $\begin{array}{c}\text { R-K } \\
\left(\mathrm{mJ} / \mathrm{m}^{2}\right)\end{array}$ & $\begin{array}{c}\text { Geometric } \\
\left(\mathrm{mJ} / \mathrm{m}^{2}\right)\end{array}$ & $\begin{array}{c}\text { spherical } \\
\left(\mathrm{mJ} / \mathrm{m}^{2}\right)\end{array}$ \\
\hline $\mathbf{3 0 3 . 2} \mathbf{K}$ & 49.89 & 42.02 & 81.98 & 30.73 & 137.03 \\
\hline $\mathbf{3 0 8 . 2} \mathbf{K}$ & 49.51 & 41.90 & 81.35 & 30.73 & 135.61 \\
\hline $\mathbf{3 1 3 . 2} \mathbf{K}$ & 48.30 & 41.10 & 79.35 & 30.24 & 131.95 \\
\hline $\mathbf{3 1 8 . 2} \mathbf{K}$ & 47.76 & 40.83 & 78.44 & 30.14 & 130.03 \\
\hline $\mathbf{3 2 3 . 2} \mathbf{~ K}$ & 47.20 & 40.63 & 77.53 & 30.11 & 128.28 \\
\hline $\mathbf{3 2 8 . 2} \mathbf{K}$ & 46.32 & 40.07 & 76.07 & 29.80 & 125.44 \\
\hline
\end{tabular}

Tables 3 and 4 prove an effect certain of the choice of chosen surface area model on the value of $\gamma_{S}^{d}$ of the solid. The difference between the results of those models can reach more than $100 \%$ of deviation. Therefore, it is not admissible to continue using Shultz et al method based on the Kiselev surface areas of molecules and to suppose at the same time that these values are considered as absolute values without changing with the temperature.

\subsection{New results on the determination of the acid base constants of sodium alginate}

In the previous section, we demonstrated the non-validity of using the dispersive component of the surface energy of the solid by using Schultz et al method [20] or Fowkes relation [22]. The value of $\gamma_{s}^{d}$ indeed depends on the choice of the molecular surface area model of molecules. These 
surface areas strongly depend on the temperature variation; However, Ugraskan et al. [1] supposed that the surface area of n-alkanes remains constant even when the temperature changes. Many errors will result by applying this classical method, certainly, because of the dependency of the specific free energy depends on the values of the surface areas of n-alkanes and polar molecules. It becomes obvious that the calculations using this parameter can no longer be considered as absolute quantitative values, and, consequently the obtained values of acid base constants of sodium alginate become wrong.

On the other hand, even when using the classical method of Schultz et al. [20], our calculations give new results different from those obtained by Ugraskan et al. [1], again because these authors supposed $\gamma_{l}^{d}$ of polar and non-polar molecules as constant.

Following Schultz et al method or Fowkes approach, $R T \ln V n$ values of the various solutes are first plotted versus $2 \mathcal{N} a\left(\gamma_{l}^{d}\right)^{1 / 2}$. The points representative of n-alkanes define the so-called "alkane straight line", and the distance between this straight line and the points corresponding to $R T \ln V n$ (polar molecule) value of polar probes are then taken as a measure of the specific free energy of adsorption $-\Delta G^{s p}$, of polar molecule on the solid. It is given, for any temperature $T$, by the following equation:

$$
-\Delta G^{\mathrm{s}}(\text { polar molecule })=R T \ln V n(\text { polar molecule })-2 \mathcal{N} a\left(\gamma_{l}^{d}\right)^{1 / 2}-C
$$

Using relation (8), we obtained the results plotted on Figure 1. 


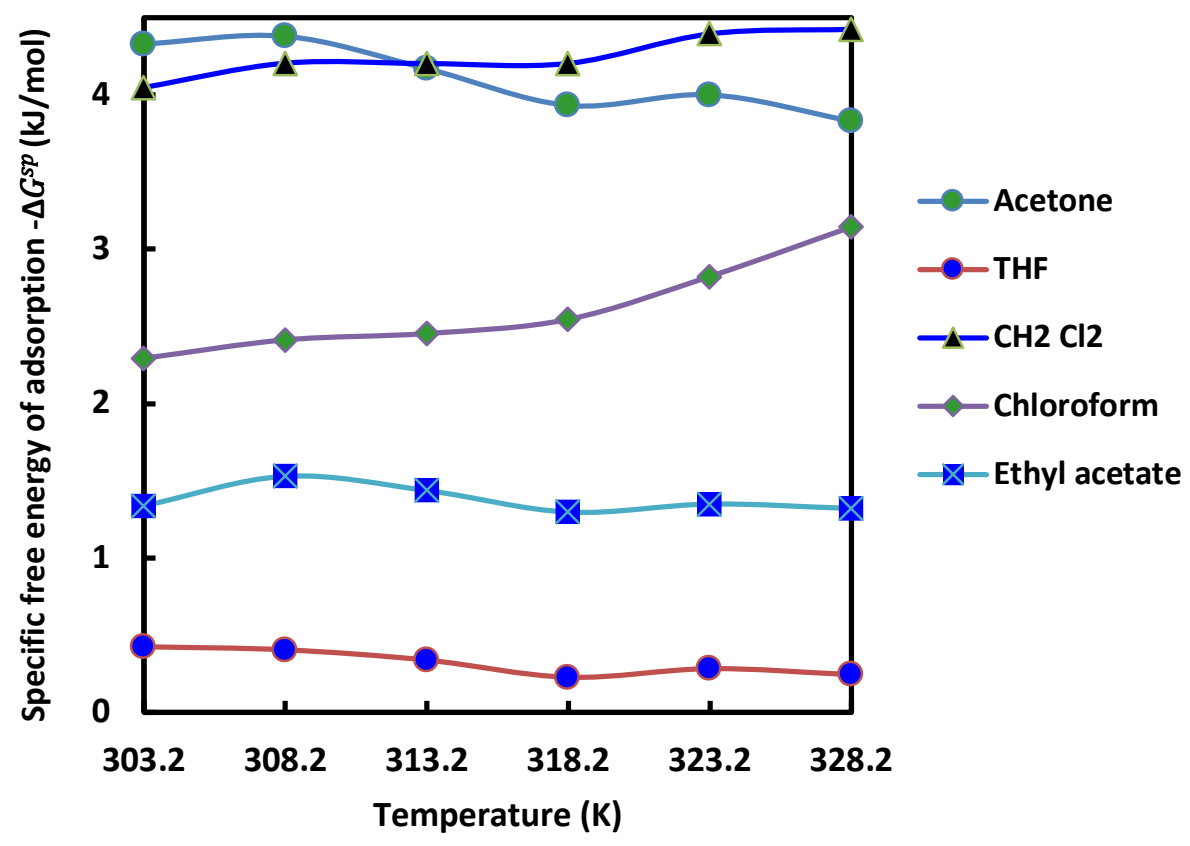

Figure 1. Evolution of the specific free energy of adsorption $\left(-\Delta G^{s p}\right)(\mathrm{kJ} / \mathrm{mol})$ of polar molecules on sodium alginate.

Our results presented in Table 5 give the various equations of the specific free energy $\left(-\Delta G^{s p}\right)$ of adsorption and the values of specific enthalpy $\left(-\Delta H^{s p}\right)$ and entropy $\left(-\Delta S^{s p}\right)$ of adsorption of polar molecules on the SA solid.

Table 5. Equations of $\left(-\Delta G^{s p}\right)$ (in $\left.\mathrm{kJ} / \mathrm{mol}\right)$ and values of $\left(-\Delta H^{s p}\right)$ (in $\left.\mathrm{kJ} / \mathrm{mol}\right),\left(-\Delta S^{s p}\right)$ (in J K${ }^{-}$ ${ }^{1} \mathrm{~mol}^{-1}$ ) and the linear regression coefficients $\boldsymbol{r}^{2}$ for different polar molecules adsorbed on sodium alginate.

\begin{tabular}{|c|c|c|c|c|}
\hline Probes & $-\Delta G^{s p}(\mathrm{~T})(\mathrm{kJ} / \mathrm{mol})$ & $-\Delta H^{s p}(\mathrm{~kJ} / \mathrm{mol})$ & $-\Delta S^{s p}\left(\mathrm{~J} \mathrm{~K}^{-1} \mathrm{~mol}^{-1}\right)$ & $r^{2}$ \\
\hline Acetone & $-\Delta G^{s p}(T)=-0.0221 \mathrm{~T}+11.089$ & 11.089 & 22.1 & 0.8693 \\
\hline THF & $-\Delta G^{s p}(T)=-0.0079 \mathrm{~T}+2.810$ & 2.8096 & 7.9 & 0.7942 \\
\hline $\mathrm{CH}_{2} \mathrm{Cl}_{2}$ & $-\Delta G^{s p}(T)=+0.0140 \mathrm{~T}-0.180$ & -0.1795 & -14 & 0.8718 \\
\hline Chloroform & $-\Delta G^{s p}(T)=+0.0319 \mathrm{~T}-7.451$ & -7.4511 & -31.9 & 0.8914 \\
\hline Ethyl acetate & $-\Delta G^{s p}(T)=-0.0044 \mathrm{~T}+2.760$ & 2.7596 & -4.4 & 0.2169 \\
\hline
\end{tabular}


Table 5 clearly shows that he values of the linear regression coefficients $\boldsymbol{r}^{2}$ for different polar molecules are comprised between 0.2169 and 0.8718 . This implies that the linearity of $\left(-\Delta G^{s p}\right)$ is not assured and therefore the values of specific enthalpy $\left(-\Delta H^{s p}\right)$ and entropy $\left(-\Delta S^{s p}\right)$ of adsorption cannot be considered as independent from the temperature. This will be another source of inaccuracies for the determination of the acid base constant. To prove that, we give on Table 6 the different values of acceptor $A N^{*}$ and donor $D N$ numbers of electrons relative to the various polar molecules with the corresponding ratios $D N / A N^{*}$ and $\left(-\Delta H^{s p}\right) / A N^{*}$.

Table 6. Values of acceptor $A N^{*}$ and donor $D N$ numbers of electrons of the different polar molecules with the corresponding ratios $D N / A N^{*}$ and $\left(-\Delta H^{s p}\right) / A N^{*}$.

\begin{tabular}{lcccc}
\hline Probes & $\boldsymbol{D} \boldsymbol{N}(\mathbf{k J} / \mathbf{m o l})$ & $\boldsymbol{A \boldsymbol { N } ^ { * } ( \mathrm { kJ } / \mathbf { m o l } )}$ & $\boldsymbol{D N} / \boldsymbol{A} \boldsymbol{N}^{*}$ & $\left(-\Delta H^{S p}\right) / \boldsymbol{A} \boldsymbol{N}^{*}$ \\
$\mathbf{C H}_{2} \mathbf{C l}_{2}$ & 0 & 16.3 & 0.00 & -0.01 \\
Chloroform & 0 & 22.7 & 0.00 & -0.33 \\
Acetone & 71.4 & 10.5 & 6.80 & 1.06 \\
Ethyl acetate & 71.1 & 6.3 & 11.29 & 0.44 \\
THF & 84.4 & 2.1 & 40.19 & 1.34 \\
\hline
\end{tabular}

The obtained results accumulate the errors committed on the values of acid KA and base KD constants of the sodium alginate. 
On Figure 2, we plotted the evolution of $\left(-\Delta H^{s p}\right) / A N^{*}$ of the various polar molecules as a function of the ratio $D N / A N^{*}$. The obtained curve on Figure 2 confirms that the linearity is not satisfied; the linear regression coefficient $r^{2}=0.6234$ very far rom 1 .

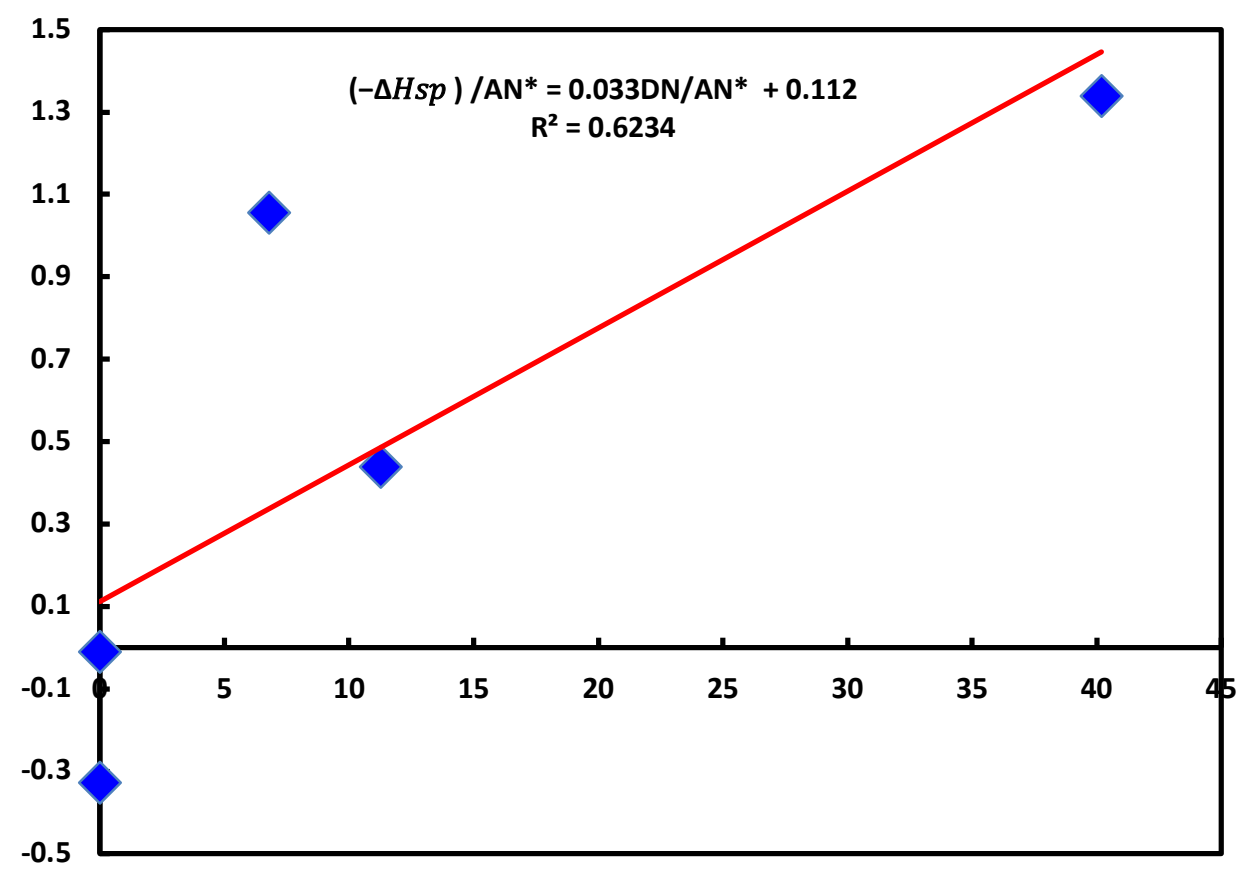

Figure 2. Evolution of of $\left(-\Delta H^{s p}\right) / A N^{*}($ in $(\mathrm{kJ} / \mathrm{mol}) /(\mathrm{kJ} / \mathrm{mol}))$ of the polar molecules versus the ratio $D N / A N^{*}$.

In order to compare between our results and those obtained by Ugraskan et al. [1], we give the following equation (even if the linearity is not satisfied):

$$
\left(\frac{-\Delta H s p}{A N^{*}}\right)=0.033\left(\frac{D N}{A N^{*}}\right)+0.112
$$

From the classic relation: 


$$
\left(\frac{-\Delta H^{S p}}{A N}\right)=K_{A}\left(\frac{D N}{A N}\right)+K_{D}
$$

One obtains the acid constants of the sodium alginate:

$$
\left\{\begin{array}{l}
K_{A}=0.033 \\
K_{D}=0.112 \\
\frac{K_{D}}{K_{A}}=3.36
\end{array}\right.
$$

These values obtained by our correction are different from those obtained by Ugraskan et al. [1]:

$$
K_{A}=0.074 ; K_{D}=0.437 \text { and } \frac{K_{D}}{K_{A}}=5.90
$$

There is large difference between our results and the results obtained by Ugraskan et al. [1] that neglected the variation of $\gamma_{l}^{d}$ of $n$-alkanes and polar molecules with the temperature.

Nevertheless, we can find for these above values a certain tendency showing effectively for sodium alginate base character rather than acid behavior with an amphoteric property.

\section{Standard deviation and error calculations}

On the other hand, we gave below some relevant calculations of the errors on the different thermodynamic parameters.

We began with the error committed on the net retention time:

$$
10^{-3} \min \leq \Delta t_{n}(\text { probe }) \leq 3 \times 10^{-3} \min
$$

The relative standard deviation on the retention time is given by the following inequalities:

$$
5 \times 10^{-5} \leq \frac{\Delta t_{n}(\text { probe })}{t_{n}(\text { probe })} \leq 10^{-4}
$$

This gives a relative standard deviation on the net retention volume:

$$
5 \times 10^{-5} \leq \frac{\Delta V_{n}(\text { probe })}{V_{n}(\text { probe })} \leq 10^{-4}
$$

And therefore, we obtain for free enthalpy of adsorption the following error:

$$
5 \times 10^{-4} \mathrm{~kJ} / \mathrm{mol} \leq \Delta\left(\Delta G_{a}^{0}\right) \leq 3 \times 10^{-3} \mathrm{~kJ} / \mathrm{mol}
$$


Moreover, the relative deviation is given by:

$$
3 \times 10^{-4} \leq \frac{\Delta\left(\Delta G_{a}^{0}\right)}{\Delta G_{a}^{0}} \leq 5 \times 10^{-4}
$$

And the error on the specific free enthalpy reads as:

$$
10^{-3} \mathrm{~kJ} / \mathrm{mol} \leq \Delta\left(\Delta G_{a}^{s p}\right) \leq 6 \times 10^{-3} \mathrm{~kJ} / \mathrm{mol}
$$

Finally, the relative error committed on the acid-base constants $K_{A}, K_{B}$ and $K$ are:

$$
1 \times 10^{-3} \leq \frac{\Delta\left(K_{A, B}\right)}{K_{A, B}} \leq 2 \times 10^{-3}
$$

Therefore, the error committed on the values of acid base constants is equal to $5 \times 10^{-3}$.

\section{CONCLUSION}

We recalculated the dispersive component of the surface energy $\gamma_{s}^{d}$ of the sodium alginate determined by Ugraskan et al. [1] by taking into account the variation of the dispersive component of the surface energy $\gamma_{l}^{d}$ of polar and non-polar molecules as a function of the temperature. This variation was neglected by Ugraskan et al.. On the other hand, we proved that $\gamma_{s}^{d}$ strongly depends on the choice of the molecular surface area model. The application of the various models of the surface areas of $\mathrm{n}$-alkanes gave an important deviation of $\gamma_{s}^{d}$ values between the different models of the surface areas. The standard deviation in certain cases was proved reaching more than $100 \%$. This leads to conclude that the determination of the specific free energy, enthalpy and entropy of adsorption of polar molecules on the sodium alginate cannot be determined with accuracy by using the Schultz method and consequently the obtained values of the acid base constants of the solid become false. Many serious errors were made by Ugraskan et al. in their calculations of the acid base constants, we proved by calculations that the results obtained by these authors are inaccurate. Nevertheless, we confirmed a certain tendency of basic character of the sodium alginate stronger than the acid character. 


\section{AUTHOR INFORMATION}

\section{Corresponding Author}

'Laboratory of Materials, Catalysis, Environment and Analytical Methods (MCEMA), Faculty of Sciences, EDST, Lebanese University, Hadath, Beirut, Lebanon.

${ }_{2}^{2}$ SATIE-IFSTTAR, University Gustave Eiffel, Campus de Marne-La-Vallée, University Gustave Eiffel, 25, allée des Marronniers, 78000 Versailles, France. Orcid.org/0000-0003-2153-7408;

Phone number: +33 7691600 92; Email: tayssir.hamieh@ul.edu.lb

\section{Funding Sources}

There no funding sources

\section{Notes}

There is no conflict of interests.

\section{REFERENCES}

[1] Ugraskan V., Isik B., Yazici O., Cakar F., Thermodynamic Characterization of Sodium Alginate by Inverse Gas Chromatography. Journal of Chemical \& Engineering Data 2020; 65 (4):1795-1801, doi: 10.1021/acs.jced.9b01074

[2] Conder JR, Young C.L. Physical measurements by gas chromatography. Eds: Wiley J and Sons, New York, 1979.

[3] Conder J. R., Locke D. C., Purnell J. H., Concurrent solution and adsorption phenomena in chromatography. I. J. Phys. Chem. 1969, 73:700-8. https://doi.org/10.1021/j100723a035.

[4] Conder J. R., Purnell J. H., Gas chromatography at finite concentrations. Part 2.-A generalized retention theory. Trans. Faraday Soc. 1968, 64:3100-11.

[5] Conder J. R., Purnell J. H., Gas chromatography at finite concentrations. Part 3.- Theory of frontal and elution techniques of thermodynamic measurement. Trans. Faraday. 1969, 65:824-38. https://doi.org/10.1039/TF9696500824 
[6] Newell E, Buckton G, Butler DA, Thielmann F, Williams DR. The Use of Inverse Phase Gas Chromatography to Measure the Surface Energy of Crystalline, Amorphous, and Recently Milled Lactose. Pharm Res 2001; 18:662-666, doi: 10.1023/A:1011089511959.

[7] Kalantzopoulou FR, Artemiacti T, Bassiotis I, Katsanos NA, Plagianakos V. Time separation of adsorption sites on heterogeneous surfaces by inverse gas chromatography. Chromatographia 2001; 53:315-320, doi: 10.1007/BF02490431.

[8] Hamieh T, Study of the temperature effect on the acid-base properties of cellulose acrylate by inverse gas chromatography at infinite dilution, J Chromatogr A. 2018, 1568, pp 168-176, DOI:10.1016/j.chroma.2018.07.025.

[9] Chow AHL, Tong HHY, Shekunov BY, York P. Letter to Editor: Use of inverse gas chromatography (IGC) to determine the surface energy and surface area of powdered materials. Pharma Res 2004; 21(9):1718-1720 doi: 10.1023/B:PHAM.0000041470.92345.e8.

[10] Askin A. Yazici DT. A study of the surface analysis of some water-soluble polymers by inverse gas chromatography. Surf. Interface Anal. 2008; 40:1237-1241, doi: 10.1002/sia.2869.

[11] Sreekanth TVM, Reddy KS. Analysis of Solvent-Solvent Interactions in Mixed Isosteric Solvents by Inverse Gas Chromatography. Chromatographia 2007; 65:326-330, doi: 10.1365/s10337-006-0149-7.

[12] Yang YC, Yoon PR. Examination of the surface properties of kaolinites by inverse gas chromatography: Acid-base properties. Korean J. Chem Eng 2007; 24:451-456, doi: 10.1007/s11814-007-0078-7.

[13] Ansari DM, Price GJ. Polymer, Chromatographic estimation of filler surface energies and correlation with photodegradation of kaolin filled polyethylene. 2004; 45:1823-1831, doi: 10.1016/j.polymer.2004.01.018.

[14] Fekete E, Móczo J, Pukánszky B. Determination of the surface characteristics of particulate fillers by inverse gas chromatography at infinite dilution: a critical approach. J. Colloid Interface Sci. 2004; 269:143-152, doi: 10.1016/S0021-9797(03)00719-7.

[15] Cline D, Dalby R. Predicting the Quality of Powders for Inhalation from Surface Energy and Area. Pharm Res 2002; 19:1274-1277, doi: 10.1023/A:1020338405947. 
[16] Santos JMRCA, Guthrie JT. Analysis of interactions in multicomponent polymeric systems: The key-role of inverse gas chromatography. Mater. Sci. Eng. R. 2005; 50:79-107, doi:10.1016/j.mser.2005.07.003.

[17] Mukhopadhyay P, Schreiber HP. Aspects of acid-base interactions and use of inverse gas chromatography. Colloids Surf. A 1995; 100:47-71, doi: 10.1016/0927-7757(95)03137-3.

[18] Gamelas JAF, Ferraz E, Rocha F. An insight into the surface properties of calcined kaolinitic clays: The grinding effect. Colloids Surf. A 2014; 455:49-57, doi: 10.1016/j.colsurfa.2014.04.038.

[19] Voelkel A, Grzeskowiak T. The use of solubility parameters in characterization of titanate modified silica gel by inverse gas chromatography. Chromatographia 2000; 51:608-614, doi: 10.1007/BF02490820.

[20] Schultz J., Lavielle L., Martin C., The role of the interface in carbon fibre-epoxy composites, Journal of Adhesion, 23(1) (1987)45-60. https://doi.org/10.1080/00218468708080469.

[21] Dorris, G. M.; Gray, D. G. Adsorption of n-alkanes at zero surface coverage on cellulose paper and wood fibers. J. Colloid Interface Sci. 1980, 77, 353-362.

[22] F.M. Fowkes, in: Surface and interfacial aspects of biomedical polymers, Vol. I, pp. 337372, Ed: J. D. Andrade, Plenum Press, New York (1985).

[23] Hamieh T, Schultz J. New approach to characterise physicochemical properties of solid substrates by inverse gas chromatography at infinite dilution. I. Some new methods to determine the surface areas of some molecules adsorbed on solid surfaces. Journal of Chromatography A. 2002; 969(1-2):17-36, doi: 10.1016/S0021-9673(02)00368-0.

[24] Hamieh T, Schultz J. Etude par chromatographie gazeuse inverse de l'influence de la température sur l'aire de molécules adsorbées. J. Chim. Phys., 1996; 93:1292-1331. doi:10.1051/jcp/1996931292. 
Figures

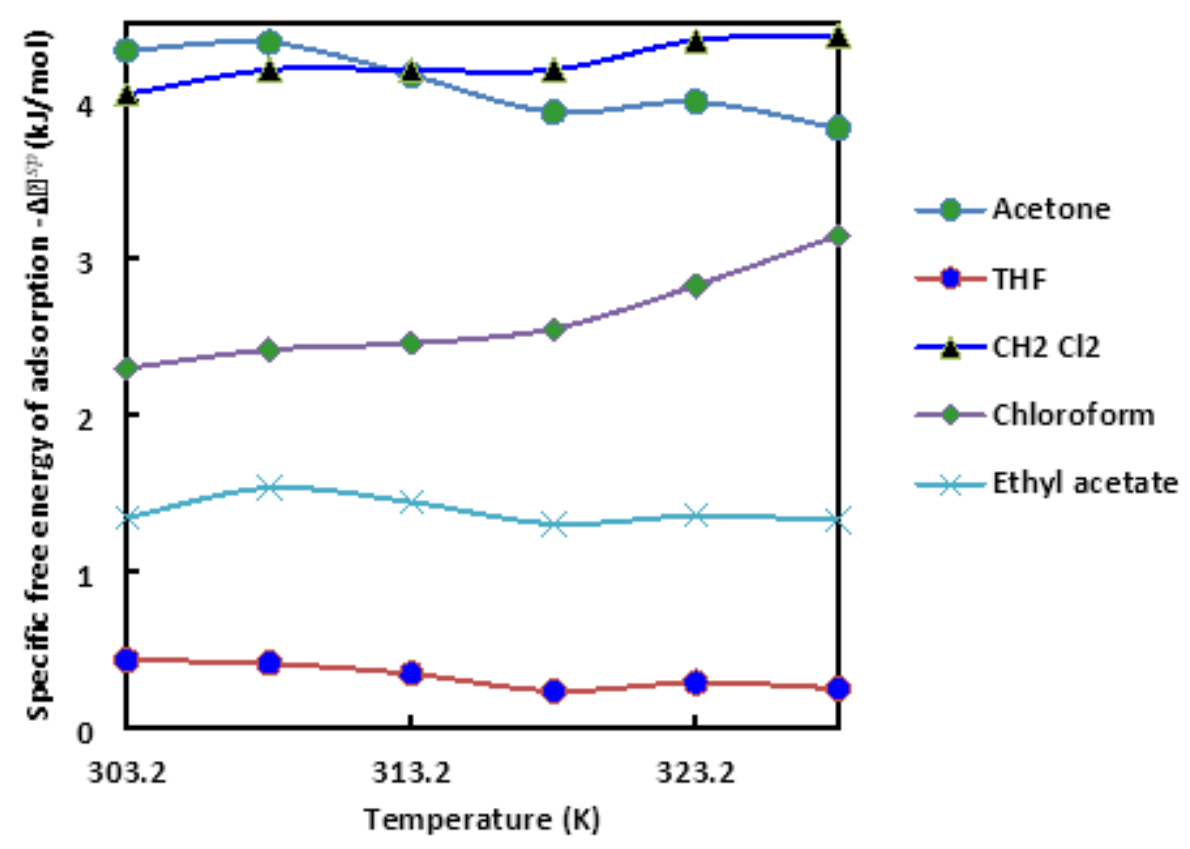

Figure 1

Evolution of the specific free energy of adsorption $\left(-\Delta \mathrm{G}^{\wedge} \mathrm{sp}\right)(\mathrm{kJ} / \mathrm{mol})$ of polar molecules on sodium alginate. 


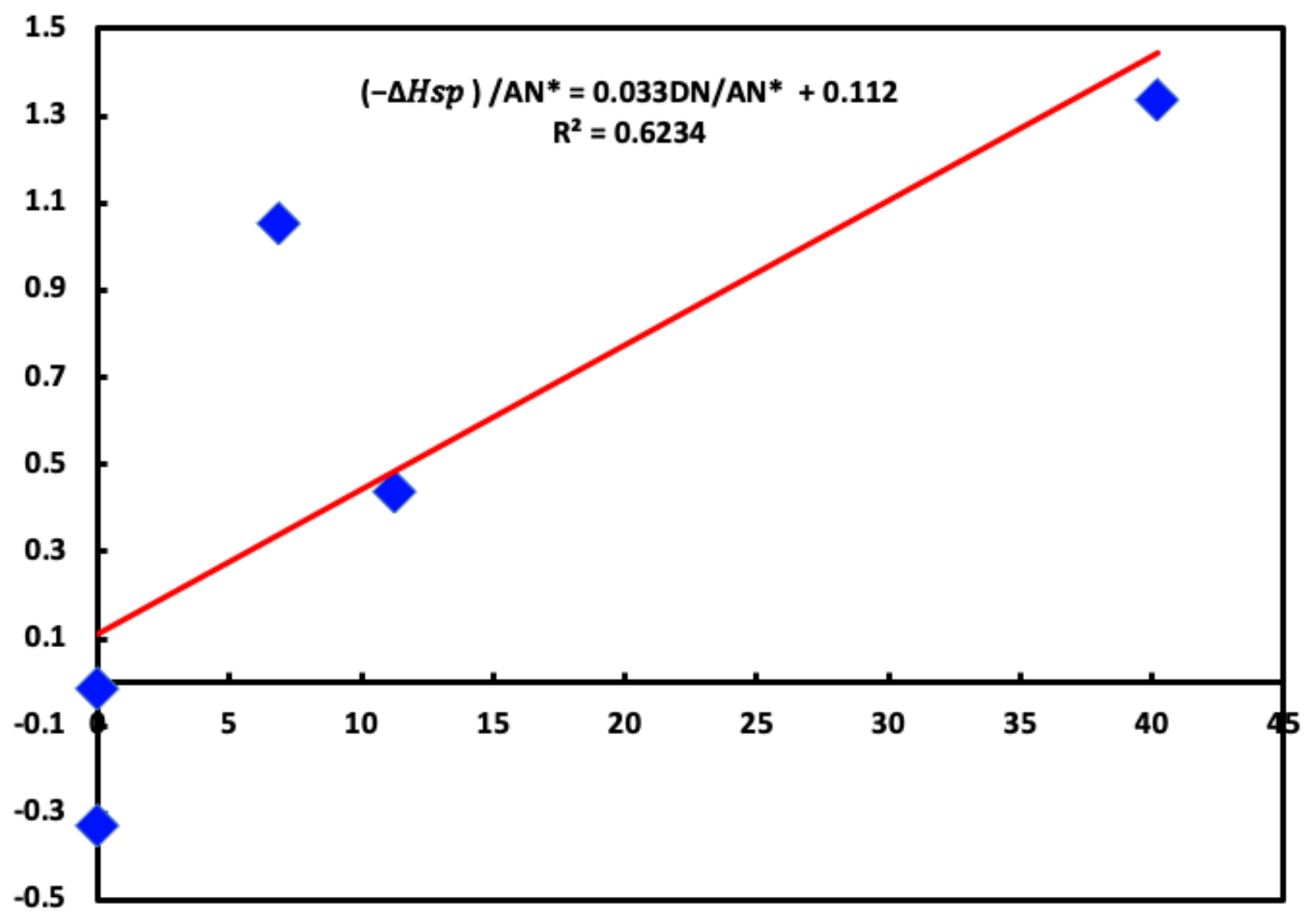

Figure 2

Evolution of of $\left(-\Delta \mathrm{H}^{\wedge} \mathrm{sp}\right) / \mathrm{AN}^{\star}$ (in $(\mathrm{kJ} / \mathrm{mol}) /(\mathrm{kJ} / \mathrm{mol})$ ) of the polar molecules versus the ratio DN/AN*. 